NBER WORKING PAPER SERIES

MACROECONOMIC MODELING FOR MONETARY POLICY EVALUATION

Jordi Galí

Mark Gertler

Working Paper 13542

http://www.nber.org/papers/w13542

\author{
NATIONAL BUREAU OF ECONOMIC RESEARCH \\ 1050 Massachusetts Avenue \\ Cambridge, MA 02138 \\ October 2007
}

The authors thank Jim Hines, Andrei Shleifer, Jeremy Stein, and Timothy Taylor for helpful comments and suggestions on an earlier draft, and Steve Nicklas for excellent research assistance. Galí is grateful to CREA-Barcelona Economics and Ministerio de Educación y Ciencia. Gertler thanks the NSF and the Guggenheim Foundation. The views expressed herein are those of the author(s) and do not necessarily reflect the views of the National Bureau of Economic Research.

(C) 2007 by Jordi Galí and Mark Gertler. All rights reserved. Short sections of text, not to exceed two paragraphs, may be quoted without explicit permission provided that full credit, including $\odot$ notice, is given to the source. 
Macroeconomic Modeling for Monetary Policy Evaluation

Jordi Galí and Mark Gertler

NBER Working Paper No. 13542

October 2007

JEL No. E31,E32,E52

\begin{abstract}
$\underline{\text { ABSTRACT }}$
We describe some of the main features of the recent vintage macroeconomic models used for monetary policy evaluation. We point to some of the key differences with respect to the earlier generation of macro models, and highlight the insights for policy that these new frameworks have to offer. Our discussion emphasizes two key aspects of the new models: the significant role of expectations of future policy actions in the monetary transmission mechanism, and the importance for the central bank of tracking of the flexible price equilibrium values of the natural levels of output and the real interest rate. We argue that both features have important implications for the conduct of monetary policy.
\end{abstract}

\author{
Jordi Galí \\ Centre de Recerca en Economia Internacional (CREI) \\ Ramon Trias Fargas 25 \\ 08005 Barcelona SPAIN \\ and NBER \\ jordi.gali@upf.edu \\ Mark Gertler \\ Department of Economics \\ New York University \\ 269 Mercer Street, 7th Floor \\ New York, NY 10003 \\ and NBER \\ mark.gertler@nyu.edu
}


Quantitative macroeconomic modeling fell out of favor during the 1970s for two related reasons. First, some of the existing models, like the Wharton Econometric model and the Brookings Model, failed spectacularly to forecast the stagflation of the 1970s..Second, leading macroeconomists leveled harsh criticisms of these frameworks. Lucas (1976), and Sargent (1981), for example, argued that the absence of an optimization-based approach to the development of the structural equations meant that the estimated model coefficients were likely not invariant to shifts in policy regimes or other types of structural changes. Similarly, Sims (1980) argued that the absence of convincing identifying assumptions to sort out the vast simultaneity among macroeconomic variables meant that one could have little confidence that the parameter estimates would be stable across different regimes. These powerful critiques made clear why econometric models fit largely on statistical relationships from a previous era did not survive the structural changes of 1970s.

In the 1980s and 1990s, many central banks continued to use reduced form statistical models to produce forecasts of the economy that presumed no structural change, but they did so knowing that these models could not be used with any degree of confidence to generate forecasts of the results of policy changes. Thus, monetary policy-makers turned to a combination of instinct, judgment, and raw hunches to assess the implications of different policy paths for the economy.

Within the last decade, however, quantitative macroeconomic frameworks for monetary policy evaluation have made a comeback. What facilitated the development of these frameworks were two independent literatures that 
emerged in response to the downfall of traditional macroeconomic modelling: New Keynesian theory and real business cycle theory. ${ }^{1}$ The New Keynesian paradigm arose in the 1980s as an attempt to provide microfoundations for key Keynesian concepts such as the inefficiency of aggregate fluctuations, nominal price stickiness, and the non-neutrality of money (e.g. Mankiw and Romer (1991)). The models of this literature, however, were typically static and designed mainly for qualitative as opposed to quantitative analysis. By contrast, real business cycle theory, which was developing concurrently, demonstrated how it was possible to build quantitative macroeconomic models exclusively from the "bottom up" - that is, from explicit optimizing behavior at the individual level (e.g. Prescott (1986)) These models, however, abstracted from monetary and financial factors and thus could not address the issues that we just described. In this context, the new frameworks reflect a natural synthesis of the New Keynesian and real business cycle approaches.

Overall, the progress has been remarkable. A decade ago it would have been unimaginable that a tightly structured macroeconometric model would have much hope of capturing real world data, let alone of being of any use in the monetary policy process. However, frameworks have been recently developed that forecast as well as the reduced form models of an earlier era (for example, Christiano, Eichenbaum, and Evans (2005), Smets and Wouters $(2003,2006))$. Because these models have explicit theoretical foundations, they can also be used for counterfactual policy experiments. A tell-tale sign that these frameworks have crossed a critical threshold for credibility is their widespread use at central banks across the globe. While these models are

\footnotetext{
${ }^{1}$ For references to NK theory see, Mankiw and Romer (1991). For references to RBC theory, see Prescott (1986).
} 
nowhere close to removing the informal dimension of the monetary policy process, they are injecting an increased discipline to thinking and communication about monetary policy.

To be sure, there were some important developments in between the traditional macroeconometric models and the most recent vintage. Frameworks such as Taylor (1979) and Fuhrer and Moore (1995) incorporated several important features that were missing from the earlier vintage of models: (i) the Phelps/Friedman natural rate hypothesis of no long-run tradeoff between inflation and unemployment, and (ii) rational formation of expectations. At the same time, however, the structural relations of these models typically did not evolve from individual optimization. The net effect was to make these frameworks susceptible to some of the same criticisms that led to the demise of the earlier generation of models (see, e.g. Sargent, 1981). It is also relevant that over the last twenty years there have been significant advances in dynamic optimization and dynamic general equilibrium theory. To communicate with the profession at large, particularly the younger generations of scholars, it was perhaps ultimately necessary to develop applied macroeconomic models using the same tools and techniques that have become standard in modern economic analysis.

Overall, our goal in this paper is to describe the main elements of this new vintage of macroeconomic models. Among other things, we describe the key differences with respect to the earlier generation of macro models. In doing so, we highlight the insights for policy that these new frameworks have to offer. In particular, we will emphasize two key implications of these new frameworks. 
1. Monetary transmission depends critically on private sector expectations of the future path of the central bank's policy instrument, the short term interest rate. Ever since the rational expectations revolution, it has been well understood that the effects of monetary policy depend on private sector expectations. This early literature, however, typically studied how expectations formation influenced the effect of a contemporaneous shift in the money supply on real versus nominal variables. ${ }^{2}$ In this regard, the new literature differs in two important ways. First, as we discuss below, it recognizes that central banks typically employ a short term interest rate as the policy instrument. Second, within the model, expectations of the future performance of the economy enter the structural equations, since these aggregate relations are built on forward looking decisions by individual households and firms. As a consequence, the current values of aggregate output and inflation depend not only on the central bank's current choice of the short term interest rate, but also on the anticipated future path of this instrument. The practical implication is that how well the central bank is able to manage private sector expectations about its future policy settings has important consequences for its overall effectiveness. Put differently, in these paradigms the policy process is as much, if not more, about communicating the future intentions of policy in a transparent way, as it is about choosing the current policy instrument. In this respect, these models provide a clear rationale for the movement toward greater transparency in intentions that central banks around the globe appear to be pursuing.

2. The natural (flexible price equilibrium) values of both output and the

\footnotetext{
${ }^{2}$ See. e.g. Fischer (1977) and Taylor (1980)
} 
real interest rate provide important reference points for monetary policy-and may fluctuate considerably. While nominal rigidities are introduced in these new models in a more rigorous manner than was done previously, it remains true that one can define natural values for output and the real interest rate that would arise in equilibrium if these frictions were absent. These natural values provide important benchmarks, in part because they reflect the (constrained) efficient level of economic activity and also in part because monetary policy cannot create persistent departures from the natural values without inducing either inflationary or deflationary pressures. Within traditional frameworks, the natural levels of output and the real interest are typically modeled as smoothed trends. Within the new frameworks they are modelled explicitly. Indeed, roughly speaking, they correspond to the values of output and the real interest rate that a frictionless real business cycle model would generate, given the assumed preferences and technology. As real business cycle theory suggests, further, these natural levels can vary considerably, given that the economy is continually buffeted by "real" shocks including oil price shocks, shifts in the pace of technological change, tax changes, and so on. Thus, these new models identify tracking the natural equilibrium of the economy, which is not directly observable, as an important challenge for central banks.

In the next section, we lay out a canonical baseline model that captures the key features of the new macro models and we draw out the corresponding insights for monetary policy. We then discuss some of the policy issues brought by the new models. We conclude by discussing some modifications of the baseline model that are necessary to take it to data, as well as other 
extensions designed to improve its realism.

\section{A Baseline Model}

In this section we lay out a baseline framework that captures the key features of the new vintage macro models and is useful for qualitative analysis. The specific framework we develop is a variant of the canonical model discussed in Goodfriend and King (1997), Clarida, Gali and Gertler (1999), Woodford (2003), and Galí (2007), among others, but modified to allow for investment. ${ }^{3}$

As with the real business cycle paradigm, the starting point is a stochastic dynamic general equilibrium model. More specifically, it is a stochastic version of the conventional neoclassical growth model, modified to allow for variable labor supply. ${ }^{4}$ As we suggested above, in order to make the framework suitable for monetary policy analysis, it is necessary not only to introduce nominal variables explicitly, but also some form of nominal stickiness. In this regard, three key ingredients that are the prominent features of the New Keynesian paradigm are added to the frictionless real business cycle model: money, monopolistic competition and nominal rigidities. We briefly discuss each in turn:

The key role of money emphasized in the new monetary models is its

\footnotetext{
${ }^{3}$ We have avoided a label for the new frameworks because a variety have been used. Goodfriend and King employ the term "New Neoclassical Synthesis," while Woodford uses "NeoWicksellian." At the insistence of a referee, Clarida, Gali and Gertler used "New Keynesian." The latter term has probably become the most popular, though it does not adequately reflect the influence of real business cycle theory.

${ }^{4}$ We note that the real business cycle model treats shocks to total factor productivity as the main driving force of business cycles. By contrast, estimated versions of the new monetary models suggest that intertemportal disturbances (i.e., shocks to either consumption or investment spending) are key. See, e.g. Galí and Rabanal (2005), Smets and Wouters (2006) or Primiceri, Schaumberg and Tambalotti (2006).
} 
function as a unit of account, i.e. as the unit in which the prices of goods and assets are quoted. The existence of money thus gives rise to nominal prices. It is important, however, to distinguish between money and monetary policy: Monetary policy affects real activity in the short run purely through its impact on market interest rates. In particular, the central bank affects aggregate spending by controlling the short term interest rate and, through market expectations of its future short rate decisions, by influencing the full yield curve. To control the short term interest rate, the central bank adjusts the money supply to accommodate the demand for money at the desired interest rate. These movements in the money supply, however, exert no independent effect on aggregate demand. Because real money balances are a negligible component of total wealth, the models are designed in a way that abstracts from wealth effects of money on spending. Thus, while monetary policy is central in these models, money per se plays no role other than to provide a unit of account.

In order to introduce price stickiness in a rigorous way, it is necessary that firms be price-setters as opposed to price-takers. For this reason, it is necessary to introduce some form of imperfect competition, where firms face downward sloping demand curves and, thus, a meaningful price-setting decision. A version of the Dixit-Stiglitz (1977) model of monopolistic competition in which each firm produces a differentiated good and sets the price for the latter while taking as given all aggregate variables provides a simple way to accomplish this and has generally been adopted by the new frameworks.

As with traditional models, what ultimately permits monetary policy to have leverage over the real economy in the short run is the existence 
of temporary nominal rigidities. Because nominal prices adjust sluggishly, by directly manipulating nominal interest rates, the central bank is able to influence real rates and hence real spending decisions, at least in the short run. The traditional models introduce sluggish price adjustment by postulating a "Phillips curve" relating inflation to some measure of excess demand, as well as lags of past inflation. By contrast, these new vintage models derive an inflation equation-often referred to as the New Keynesian Phillips curve-explicitly from individual firms' price setting behavior, as we describe below.

We now turn to a description of our canonical framework. As with the traditional framework, it is convenient to organize the system into three blocks: aggregate demand, aggregate supply, and policy. Further, it is possible to represent each sub-sector by a single equation. In an appendix available with the online version of this paper (at http://www.e-jep.org), we build up the aggregate demand and aggregate supply relationships in detail. In what follows, we present the condensed aggregate demand and supply equations along with an informal motivation. By adding an additional relation that describes monetary policy, it is then possible to express the model as a simple three equation system, similar in spirit to the way traditional models have been represented. The main difference with the traditional framework, of course, is that the new vintage of models are built on explicit micro foundations. 


\subsection{Aggregate Demand/Supply: A Compact Repre- sentation}

In developing this baseline model, it is useful to keep in mind that what monetary policy can influence is the deviation of economic activity from its natural level. Within our baseline model, the natural level of economic activity is defined as the equilibrium that would arise if prices were perfectly flexible and all other cyclical distortions were absent. In the limiting case of perfect price flexibility, accordingly, the framework takes on the properties of an real business cycle model. One difference with the latter is that because there is monopolistic competition as opposed to perfect competition, the natural level of economic activity is below the socially efficient level. However, this distinction does not affect the nature of the associated cyclical dynamics of the natural level of economic activity which, within our baseline framework, resemble those of an real business cycle model with similar preferences and technology.

Aggregate Demand. The aggregate demand relation is built up from the spending decisions of a representative household and a representative firm. In the baseline model, both capital and insurance markets are perfect. Within this frictionless setting, the household satisfies exactly its optimizing condition for consumption/saving decisions. It thus adjusts its expected consumption growth positively to movements in the expected real interest rate. Similarly, with perfect capital markets, the representative firm satisfies exactly its optimizing condition for investment: it varies investment proportionately with Tobin's $q$, the ratio of the shadow value of installed capital to the replacement value. 
From the individual spending decisions, it is possible to derive an IS curve-type equation that relates aggregate demand inversely to the short term interest rate, similar in spirit to that arising in a traditional framework. In contrast to the traditional model, however, expectations of the future value of the short term rate matter as well. They do so by influencing long term interest rates and asset prices.

In particular, let $\widetilde{y}_{t}$ be the percentage gap between real output and its natural level, let $\widetilde{r r}_{t}^{l}$ be the gap between the long term real interest rate and its natural level, and let $\widetilde{q}_{t}$ be the corresponding percentage gap in Tobin's $q^{5}$. Then by taking log-linear approximations of both the baseline model and the flexible price variant, it is possible to derive an aggregate demand equation that relates the output gap, $\widetilde{y}_{t}$, inversely to the real interest rate gap , $\widetilde{r r}_{t}^{l}$, and positively to the gap in Tobin's $q, \widetilde{q}_{t}$, as follows:

$$
\widetilde{y}_{t}=-\gamma_{c} \sigma \widetilde{r r}_{t}^{l}+\gamma_{i} \eta \widetilde{q}_{t}
$$

where $\gamma_{c}$ and $\gamma_{i}$ are the shares of consumption and investment, respectively, in steady state output, $\sigma$ is the intertermporal elasticity of substitution, and $\eta$ is the elasticity of the investment/capital ratio with respect to Tobin's $q$. In effect, this equation relates the output gap to the sum of two terms. The first corresponds to the consumption gap and the second to the investment gap.

In particular, the consumption gap moves inversely with the long term real interest rate gap $\widetilde{r r}_{t}^{l}$. Intuitively, if the long term real rate is above its

\footnotetext{
${ }^{5}$ To be clear, we define the natural level of economic activity in any given period period $\mathrm{t}$, conditional on the beginning of period capital stock. Monetary policy has no effect on the natural level of economic activity as we have defined. Monetary policy can affect the path of the capital stock, though these effects are typically small in percentage terms under reasonable parameterizations of the model.
} 
natural value, households will be induced to save more than in the natural equilibrium and, hence, consumption will be lower. Similarly, if $q$ is above its natural value, firms will be induced to invest more than they would under flexible prices.

In order to link aggregate demand to monetary policy, it is useful to define the short term real interest rate gap, $\widetilde{r r}_{t}$, as the difference between the short term real rate and its natural equilibrium value, $r r_{t}^{n}$, that is

$$
\widetilde{r r}_{t} \equiv\left(r_{t}-E_{t} \pi_{t+1}\right)-r r_{t}^{n}
$$

where $r_{t}$ is the short term nominal interest rate and $\pi_{t+1}$ is the rate of inflation from $t$ to $t+1$. We note next:

(i) $\widetilde{r r}_{t}^{l}$ depends positively on current and expected future values of $\widetilde{r r}_{t}$.

(ii) $\widetilde{q}_{t}$ depends inversely on current and expected future values of $\widetilde{r r}_{t}$.

Proposition (i) emerges from the link between long term interest rates and current and expected short term interest rates implied by the expectation hypothesis of the term structure Proposition (ii) arises Tobin's $q$ depends on the discounted returns to capital investment, where the discount rates depend on the expected path of short term real interest rates.

Thus the mechanism through which monetary policy influences aggregate demand works can be thought of as working as follows. Given the sluggish adjustment of prices, by varying the short term nominal rate the central bank is able to influence the short-term real interest rate and, hence, the corresponding real interest rate gap. Thus, through its current and expected future policy settings it is able to affect the corresponding path of $\widetilde{r r}_{t}$ and, in turn, influence the long term real rate gap, $\widetilde{r r}_{t}^{l}$, and the gap in Tobin's $q, \widetilde{q}_{t}$. 
As in the traditional models, the framework can incorporate exogenous fluctuations in government purchases or other aggregate demand components. These fluctuations influence both the natural level of output and the natural real interest rate. However, the form of the aggregate demand equation is not affected, since this relation is expressed in terms of gap variables.

Finally, we note that the compact form of the aggregate demand curve depends on the assumption of perfect capital markets, so that both the permanent income hypothesis for consumption and the $q$ theory for investment are valid. As we discuss later, recent work relaxes the assumption of perfect capital markets.

Aggregate Supply: The aggregate supply relation evolves from the price setting decisions of individual firms. To capture nominal price inertia, it is assumed that firms set prices on a staggered basis: each period a subset of firms set their respective prices for multiple periods. Under the most common formulation, due to Calvo (1983), each period a firm adjust its price with a fixed probability that is independent of history. ${ }^{6}$ This assumption is not an unreasonable approximation of the evidence (Nakamura and Steinsson (2007) and Alvarez (2007)).

Under flexible prices, during each period firms set price equal to a constant markup over nominal marginal cost. With staggered price setting, firms that are able to adjust in a given period set price equal to a weighted average

\footnotetext{
${ }^{6}$ The idea of using staggering to introduce nominal inertia is due to Fischer (1997) and Taylor (1980), who used it to describe nominal wage setting. A virtue of the Calvo formulation is that is facilitates aggregation. Because the adjustment probability is independent of how long a firm has kept its price fixed, it is not necessary to keep track of when different cohorts of firms adjusted their prices.
} 
of the current and expected future nominal marginal costs. The weight on a given future nominal marginal cost depends on the likelihood that the firm's price will have remained fixed until that particular period, as well as on the firm's discount factor. The firms that do not adjust prices in the current period simply adjust output to meet demand, given that the price is not below marginal cost. Thus, the nominal price rigidities permit output to fluctuate about its natural level. Given that firms' supply curves slope upwards, further, these demand induced fluctuations lead to countercyclical markup behavior.

By combining the log-linear versions of the optimal price setting decision, the price index and the labor market equilibrium, one can obtain the following structural aggregate supply relation:

$$
\pi_{t}=\beta E_{t} \pi_{t+1}+\kappa \widetilde{y}_{t}+u_{t}
$$

where, following Clarida, Gali, and Gertler (1999), $u_{t}$ is interpretable as a "cost push shock." The equation has the flavor of a traditional Phillips curve in the sense that it relates inflation $\pi_{t}$ to excess demand as measured by $\widetilde{y}_{t}$ and also a term that reflects inflation expectations, in this case $\beta E_{t} \pi_{t+1}$.

In sharp contrast to the traditional Phillips curve, however, the optimization based-approach here places tight structure on the relation. The coefficient on expected inflation, $\beta$, is the household's subjective discount factor. The slope coefficient on excess demand $\kappa$, in turn, is a function of two sets of model primitives. The first set reflects the elasticity of marginal cost with respect to output. The less sensitive is marginal cost to output (i.e., the flatter are supply curves), the less sensitive will price adjustment be to movements in output (i.e., the smaller will be $\kappa$ ). The second set 
reflects the sensitivity of price adjustment to movements in marginal costs. This includes the parameter that governs the frequency of price adjustment. The lower this frequency, the fewer the firms adjusting in any period, and hence the less sensitive inflation will be to marginal cost and the smaller will be $\kappa$.. Also potentially relevant are pricing complementarities that may induce firms to minimize the variation in their relative prices. These pricing complementarities, know in the literature as "real rigidities," induce firms that are adjusting prices to want to keep their relative price close to the non-adjusters. The net effect of real rigidities is to reduce $\kappa$ and thus reduce the overall sensitivity of inflation to output (Ball and Romer (1990) and Woodford (2003)). ${ }^{7}$

In addition, the cost push shock, $u_{t}$, has a strict theoretical interpretation. In the absence of market frictions other than nominal price rigidities $u_{t}$ effectively disappears, making $\widetilde{y}_{t}$ the exclusive driving force for inflation. Key to this result is that firms are adjusting price in response to expected movements in marginal cost. In this benchmark case, deviations of real marginal cost from its natural value are approximately proportionate to $\widetilde{y}_{t}$, effectively making the latter a sufficient statistic for the former. Roughly speaking, movements in output above the natural level raise labor demand, inducing an increase in wages and and a reduction in the marginal product of labor, both of which tend to raise firms' marginal costs. With other types of market frictions present, however, variation in firms' marginal costs need no longer be simply proportional to excess demand. Suppose, for example, due

\footnotetext{
${ }^{7}$ Most of the empirical evidence points to low values for $\kappa$ (Gali and Gertler (1999)). However, with real rigidities present it is possible to reconcile the low estimates with the microeconomic evidence on the frequency of price adjustment, as recently summarized in Steinsson and Nakumura (2007), among others.
} 
to some form of labor market power, real wages rise above their competitive equilibrium values. Holding constant $\widetilde{y}_{t}$ firms' marginal costs increase due to the wage increase, thus fueling inflation. In this instance, the cost push term captures the impact on inflation. More generally, $u_{t}$ encapsulates variation in real marginal costs that is due to factors other than excess demand. In the formulation here we will simply treat $u_{t}$ as exogenous. As we discuss in section 4 and the appendix, however, more general formulations of this model introduce endogenous variation in $u_{t}$ typically by allowing for wage rigidity, introduced much in the same manner as price rigidity (via staggered nominal wage setting.) Indeed, with wage rigidity present, $u_{t}$, will depend on conventional real shocks such as oil shocks and productivity shocks.

Another important way that the new Phillips curve differs from the old is that it is fully forward looking. Inflation depends not only on the current values of $\widetilde{y}_{t}$ and $u_{t}$, but also on the expected discounted sequence of their respective future values. This forward-looking property of inflation implies that a central bank's success in containing inflation depends not only on its current policy stance, but also on what the private sector perceives that stance will be in the future. We elaborate on this in the next section.

In the meantime, we note that this forward looking process for inflation contrast sharply with the traditional Phillips curve, which typically relates inflation to lagged values as well as some measure of excess demand, without any explicit theoretical motivation. In the baseline version of the new Phillips curve, arbitrary lags of inflation do not appear. ${ }^{8}$

\footnotetext{
${ }^{8}$ Gali and Gertler (1999) and Gali, Gertler and Lopez-Salido (2005) estimate a hybrid version of the new Phillips curve where inflation depends on both lagged and expected future inflation. Lagged inflation enters because a fraction of firms set prices using a backward-looking rule of thumb. The estimates suggest a weight of roughly .65 on
} 
The debate over the exact specification of the Phillips curve, of course, has important consequences for the kind of constraints that a central bank faces for its policy choices. The traditional Phillips curve implies that the central bank faces a short run trade-off between inflation and real activity: Since expectations play no role in inflation dynamics, the only way to reduce inflation in the short run is to contract economic activity. In contrast, with the new Phillips curve expectations play a critical role and, as a result, the short run trade-off emerges in a more subtle way. In particular, absent movements in the cost push term $u_{t}$, there is no short run trade-off, so long as the central bank can credibly commit to stabilizing both current and expected future inflation. To see this, note that when no cost push term exists inflation depends only on the current and expected future values of the output gap. Then in this instance, a central bank can maintain price stability by adjusting short term interest rates in order to stabilize the output gap. It can do so by setting the current nominal interest rate equal to the natural real rate and by committing to stick to this policy in the future. Of course, this presumes both that the central bank can perfectly identify the natural real rate of interest and also that it can credibly commit to a path for the future nominal rate. We return to this issue in the next section..

Even with perfect information and perfect credibility, a short run tradeoff between the output gap and inflation can emerge if cost push pressures are present. In this instance, inflation depends on current and expected movements in $u_{t}$ as well as $\widetilde{y}_{t}$. The only way to offset this cost push pressure on expected future inflation and .35 on lagged inflation for the U.S.. Thus, while lagged inflation appears a factor in inflation dynamics, forward looking behavior is dominant. Cogley and Sbordone (2006), further, present evidence to suggest that once one allows for shifting trend inflation, lagged inflation disappears. 
inflation is for the central bank to contract economic activity. We emphasize that this basic insight on how cost pressures may introduce a short run trade-off carries over to a setting where these pressure are endogenous due to nominal wage rigidity.(Erceg, Henderson and Levin (2000)).

Finally, the forward looking Phillips curve can give rise to a potential credibility problem distinct from the one originally emphasized by Kydland and Prescott (1977) or Barro and Gordon (1981). This earlier literature stressed the temptation of central banks to unexpectedly push output above the natural level. For central banks unable to make a credible commitment to keeping inflation low, the resulting outcome would be an inefficiently high level of inflation. This potentially credibility problem, known as "inflation bias", is also explicitly present in the new vintage models since within these frameworks the natural level of output is in general below the socially efficient level, due to the presence of imperfect competition. However, the forward looking nature of inflation within these new frameworks suggests another potential pitfall of discretion, know in the literature as "stabilization bias" (Clarida, Gali and Gertler (1999) and Woodford (2003)). In response to expected cost pressures, a central bank would like to claim it will be tough in the future, and will contract output as necessary, in order to fight current inflation without having to contract output below its natural level today. If the central bank could make this claim credible, it could reduce current inflation without reducing current output, due to the expectations effect. The problem is that in the absence of a well established reputation (or some other way of "tying its hands"), the central bank's claim is not likely to be credible: The private sector will recognize that once the next period arrives, 
the central bank will be tempted to delay again contracting the economy (that is,. the initial plans are time-inconsistent).

Thus, the extent to which the central bank is credible regarding its future policies will affect the short-run tradeoff between inflation and output gap stabilization. Given the twin problems of inflation and stabilization bias, the new frameworks explicitly suggest a need for central banks to establish credibility in monetary policy management,

The representation of this aggregate supply/aggregate demand framework can be reduced to a system of difference equations describing the evolution of the output gap and inflation as a function of two exogenous variables (the natural rate of interest and the cost push shock), as well as the path of the nominal short term rate $r_{t}$. The latter is determined, directly or indirectly, by the decisions of the central bank. Thus, to close the model, we need to provide a description of the way monetary is conducted.

\subsection{Monetary Policy}

Each period the central bank chooses a target for the short term interest rate, as a function of economic conditions. To attain that rate, the central bank adjusts the money supply to meet the quantity on money demanded at the target interest rate. Why not simply do the reverse: set the nominal money stock and let the interest rate adjust? One reason is the potential instability of money demand suggested by the evidence. Under monetary targeting, this instability would translate into interest rate volatility that could harm the real economy. ${ }^{9}$

\footnotetext{
${ }^{9}$ It is important to recognize, however, that the quantity theory of money still holds in the steady state, even with the interest rate as the policy instrument and a purely
} 
A simple interest rate feedback rule that has desirable stabilizing properties and also some empirical appeal as a description of what central banks do in practice takes the following form:

$$
r_{t}^{\tau}=r r_{t}^{n}+\phi_{\pi} \pi_{t}+\phi_{y} \widetilde{y}_{t}
$$

where $\phi_{\pi}>1, \phi_{y} \geq 0$ and where $r_{t}^{\tau}$ is the central bank's target for the shortterm nominal interest rate. With zero inflation and no excess demand, the rule has the central bank adjust the nominal rate to track movements in the natural real rate, $r r_{t}^{n}$.

Note that the rule implies that with inflation and the output gap at zero, the central bank keeps the current and expected future real interest rate gaps at zero. On the other hand, if the economy is "overheating" with a positive output gap and positive inflation, the rule has the central bank raise nominal rates. The feedback coefficient on inflation exceeds unity, implying that nominal rates go up more than one for one with inflation. This ensures that the central bank raises real rates sufficiently to contract demand (by inducing a positive sequence of real interest rate gaps.) Conversely, as the economy weakens and inflation declines, the rule has the central bank ease sufficiently to provide demand stimulus.

This interest rate rule is often referred to as a "Taylor" rule. The reason is that after a period of considerable focus on money growth rules in the

passive role for money demand (see, e.g., Woodford, 2006). Under standard specifications of money demand, the ratio of real money balances to output is constant in a steady state with constant inflation. Since this ratio is constant, within the steady state there is a proportionate relation between the growth rate of the money stock and inflation, as the quantity theory suggests, and independently of whether the central bank has a monetary target or not. Outside the steady state, however, the simple aggregate demand and supply described earlier characterizes output and inflation dynamics conditional on the expected path of interest rates. 
academic literature, Taylor $(1993,1999)$ argued that an interest rate rule of this type has desirable stabilizing properties and avoids the pitfalls of moneybased rules that some central banks had adopted in the previous decades. Taylor also showed that a version of this rule with a constant natural real interest rate and detrended output as the measure of the output gap does a good job of describing actual monetary policy in the late 1980s. The values of the feedback coefficients in the rule plotted against the data were $\phi_{\pi}=1.5$ and $\phi_{y}=0.5$. The key feature that Taylor emphasized was that $\phi_{\pi}$ safely exceeded unity, thus ensuring that the policy induces real rates to move to offset inflationary pressures. This feature has been dubbed the "Taylor principle",(by Woodford (2001)). A number of authors, including Clarida, Galí and Gertler (1998, 2000), have argued that during the late 1960s and 1970s, the major central banks may have failed to abide by the Taylor principle, thus contributing to both the high nominal and real instability over this period.

For the very short sample period Taylor examined in his original paper, it may be reasonable to treat the natural rate of interest as constant and presume the natural level of output is captured by a smooth trend. But over a longer sample it would be unwise for a central bank to do this. In addition, the simple rule that Taylor studied does not capture central banks' tendency to smooth interest rates. A rule that comes closer to capturing the data has the central banks move interest rates toward the target rate $r_{t}^{\tau}$, using the following partial adjustment rule:

$$
r_{t}=(1-\rho) r_{t}^{\tau}+\rho r_{t-1}
$$

where $\rho$ is a smoothing parameter which is usually estimated to be between 
0.6 and 0.9 using quarterly data.

\section{Using the Model for Monetary Policy Eval- uation}

In this section we show how the model may be used to evaluate different scenarios for the course of monetary policy. In the process, we illustrate the two major implications that the new vintage models have for policy-making that we emphasized in the introduction: (i) the importance of managing expectations of future policy; and (ii) the need to track movements in the economy's natural equilibrium.

To evaluate different policy strategies, of course, one has to have in mind some kind of objective criterion. Here we note that a traditional objective for central banks is to maintain price stability and output at its natural level. In the case of the Federal Reserve, this is objective is known as the dual mandate. Because the new vintage of models evolve from individual optimization, it is possible in principle to derive a welfare criteria for the central bank explicitly by taking a quadratic approximation of the utility function of the representative household. For example, in a slightly simpler version of our model, one can derive something akin to a dual mandate endogenously. That is, it is possible in this instance to derive a loss function for the central bank that is quadratic in deviations of inflation from zero and deviations of output from the socially efficient (competitive equilibrium) level. ${ }^{10}$

Here we simply presume, as in practice, that the central bank has in mind

\footnotetext{
${ }^{10}$ See, e.g. Rotemberg and Woodford (1999).
} 
a dual objective in terms of stabilizing inflation and the output gap, without being overly precise about the exact form. We presume further that the natural level of output is sufficiently close to the socially efficient value, so that the welfare-relevant gap is simply the deviation of output from its natural level. With this rough criteria in mind, we subject the model economy to several kinds of disturbances and then evaluate the performance of alternative monetary policy strategies. These experiments are representative of the policy evaluation exercises that central banks can do in practice.

We present two numerical simulations of the model. The first illustrates how there may be gains to a central bank from managing expectations of the future course of monetary policy. These gains take the form of improving the short run tradeoff between inflation and output. The second experiment demonstrates the importance to the central bank of accounting for movements in the economy's natural (i.e., flexible price) equilibrium in making its policy decisions.

In order to perform the simulations, we need to choose numerical values for the various model parameters. The appendix for the on-line version of this paper lists all the model parameters along with the values used for the simulations. By and large, the values we use are conventional in the literature. We now turn to the model experiments.

Experiment 1: Managing expectations. Here we illustrate how a central bank's ability to credibly signal its future policy intentions influences its ability to maintain price and output gap stability. We suppose that a central bank intends to pursue an interest policy that aggressively fights inflation. We then consider two different scenarios: In the first, the central 
bank is able to successfully signal its intentions to the private sector. In the second, the private sector believes that the central bank is likely to accommodate inflation.

We assume that the economy is hit by "cost push" pressures in the form of a persistent increase in $u_{t}$ (see equation 2). An example of this kind of scenario might be a situation where workers resist moderating real wage growth for a period of time in the wake of a decline in trend productivity growth In this situation, unit labor costs and hence firms' marginal costs rise, which in turn creates inflationary pressures, as implied by equation (2). We assume that the cost push shock obeys a first order autoregressive process, with an autocorrelation of 0.95 . This choice permits our model to capture the high degree of autocorrelation of inflation in the data.

The aggressive policy that the central bank plans to pursue is an interest rate rule that responds only to inflation and not the output gap. The coefficient on inflation $\phi_{\pi}$ is 1.5 , implying that the central bank raises nominal rates a hundred and fifty basis points, for every hundred basis point rise in inflation. In the first case the private sector accepts that the central bank will follow this rule indefinitely into the future. In the second case the private sector believes instead the central bank will instead pursue a passive rule that does not try to curb inflationary pressures. The accommodative rule that the private sector perceives the central bank will follow in the future has a feedback coefficient on inflation of 1.0,implying only a one-for-one response of nominal rates to inflation. ${ }^{11}$ In this spirit, the private sector views any departures of the current short term interest from this rule as purely

\footnotetext{
${ }^{11}$ Strictly speaking we assume $\phi_{\pi}=1.001$, in order to guarantee the existence of a unique stationary equilibrium.
} 
transitory.

We assume further that in the case where it is not credible, the central bank nonetheless tries to curtail inflation by raising the nominal interest rate sufficiently to contract aggregate demand by the same amount each period as if it was pursuing a perfectly credible aggressive policy with $\phi_{\pi}=1.5$. In particular, each period the central bank raises the nominal rate as needed in order to contract output by the same amount that would occur under a credible aggressive policy. The problem it faces, however, is that the market is expecting the accommodative policy. As a result, to engineer the same output contraction that would arise under a credible aggressive policy, the central bank needs to increase sharply the current nominal interest rate: Because the private sector expects reversion to the accommodating policy in the future, to contract demand sufficiently the central bank must compensate with an extra large increase in the current short term rate. Put differently, under the credible aggressive policy, the central bank exploits its ability to influence expectations over the entire yield curve. It contracts demand today not only by raising short term rate today but also by creating expectations that future short rates will be sufficiently high as well (inducing expectations of a lower output gap in the future). Without the leverage over market expectations, the central bank is left with the current short rate as the only way to influence current demand.

Table 1 shows the responses of inflation and the output gap that the model economy generates for the first two years after the costs push shock. It does so for both the case where the central bank is credible and for the case it is not. Period 0 is the time of the shock. In each case we report the change in 
inflation and output one and two years after the shock. Under each scenario the central bank raises interest rates to counteract the inflationary pressures. Given how we designed the experiment, the decline in output is the same in each case. ${ }^{12}$ However, the rise in inflation is much larger in the case where the central bank is perceived to be accommodative as opposed to credibly aggressive. This occurs because inflation depends on expectations of future demand conditions, in addition to current conditions. What this experiment illustrates is that being able to effectively manage expectations improves the short run tradeoff between output and inflation stabilization that the central bank faces. Market perceptions of accommodation yield higher inflation for a given current contraction of economic activity. It follows that to generate a given slowdown of inflation, these perceptions of accommodation force the central bank to engineer a larger contraction in output than it would otherwise be necessary.

This experiment may also provide insight to how monetary policy differs today from the period of the Great Inflation in the 1970s. Whenever the Federal Reserve attempted to reign in inflation during this earlier period, the effort either had little success or proved costly in terms of output loss. In recent times the reverse seems true. In our view, the explanation for the difference is that in the current era the Federal Reserve has established a credible long term commitment to maintain price stability, which was not the case in the earlier period. This also helps explain why the current Federal Reserve places so much emphasis on communicating its future intentions.

Experiment 2: Tracking the natural equilibrium. We next suppose

\footnotetext{
${ }^{12}$ Since the cost push shock does not affect the natural level of output, the response of the output gap is the same as the response of output in this case.
} 
that the economy is hit with a shock to productivity. In contrast to the previous experiment, the disturbance influences the natural values of output and the real interest rate. Thus we now distinguish between movements in the output gap versus movements in output. Our goal here is to illustrate why it is important for the central bank in setting interest rates to account for the movement in the economy's natural equilibrium.

In particular, we assume that technology growth obeys an $\operatorname{AR}(1)$ with autoregressive coefficient equal to 0.5 . We then determine the response of the model economy to an unanticipated increase in technology growth under two different policy scenarios. Under the first, the central bank adjust the nominal interest rate in response to movements in both the natural rate of interest and inflation, exactly as the policy rule (3) suggests. In the second case the central bank pays no attention to movements in the natural rate of interest, and responds simply to inflation. In each case we set the feedback coefficient on inflation $\phi_{\pi}=1.5$, which corresponds to the aggressive case studied above.

Table 2 reports the responses of inflation and output. The rise in productivity growth induces an increase the natural rate of interest. ${ }^{13}$ Observe that under the policy rule that adjust for movements in the natural rate, inflation remains stabilized. In this instance the response of output mirrors the response of the natural level of output. Put differently, even though the

\footnotetext{
${ }^{13}$ Specifically, up to a first order, the natural rate of interest is equal to the expected growth of consumption under the flexible price equilibrium times the coefficient of relative risk aversion. This relation comes from the consumption euler equation that applies in the flexible price equilibrium and assumes perfect capital markets, etc. The rise in the natural rate of interest thus reflects the facts that the shock to productivity growth produces an expected increase in consumption growth in the flexible price equilibrium.
} 
productivity shock generates a rise in output, the gap between output and its natural value remains at zero. Because the output gap doesn't move, neither inflationary or deflationary pressures emerge.

By contrast, if the central bank fails to account for movements in the natural rate, it does not increase the nominal rates sufficiently to curtail inflation. Because the real rate is below the natural rate for at least a year under this scenario, excess demand emerges. Output increases relative to the natural level of output. For a period, the output gap is positive and, accordingly, inflation rises above trend. This is reversed after a year. Inflation falls slightly below trend. The reason is that the natural rate eventually falls below trend for a persistent period due to extra capital accumulation from above trend investment. By failing to compensate, the central bank keeps the real rate a bit too high relative to the natural rate.

In reality, of course, the central bank cannot directly observe the natural rate of interest. However, as economic conditions change, the central bank has to draw inferences about the likely consequences for the natural rate. Indeed, a number of central banks including the Federal Reserve, are using models of the type we have been discussing to try to identify the natural rate. Of course, indirect methods are also used. In particular, the behavior of inflation tells the central bank something about the underlying natural rate. Inflation above what it might expect may in principle be a sign that the natural rate is higher than it was perceived, and vice-versa. 


\section{Extensions and New Directions}

Our baseline model, while useful for pedagogical purposes, is too parsimonious to be taken to the data or to be used in actual policy simulations. It is thus not surprising that much recent work, largely conducted by research teams based in central banks or international institutions, has aimed at making the model more realistic, by adding a variety of features that are likely to enhance its fit of the data. ${ }^{14}$ We now describe some of those features and then briefly discuss some extensions that are in progress.

Taking the Model to Data: The macroeconomic variables within the baseline model appear to display greater persistence in practice than this simple framework can capture. For example, the evidence suggests that a transitory exogenous shift in monetary policy produces a delayed hump-shaped response of the key quantity variables, output, consumption and investment. The baseline model instead predicts an instantaneous jump in these variables, followed by a monotonic response to trend. The reason for this is the absence of frictions that may slow down the adjustment in either consumption or investment to either current shocks, news about the future, or both.

A common way to address this issue is to introduce adjustment costs. In the case of consumption, a typical approach is to assume the presence of habits in agents' preferences, by making current utility a function of the deviation of current consumption from a benchmark usually set to be a (large)

\footnotetext{
${ }^{14}$ Early examples of models embedding some of the features discussed here were Smets and Wouters (2003) and Christiano, Eichenbaum and Evans (2005). Some of the recent medium-scale models developed by policy institutions, built on those early examples, include the New Area Wide Model developed at the ECB (see, e.g., Coenen, McAdam and Straub (2006)), the SIGMA model of the Board of Governors (Erceg, Guerrerri and Gust (2006)), and the GM model developed by the IMF (Bayoumi (2004)).
} 
fraction of lagged consumption. Similarly, in order to make the model consistent with the sluggish response of investment to shocks, it is sometimes assumed that adjustment costs arise as a result of changes in the level of investment, as opposed to the level of investment itself (relative to the capital stock) as found in the standard Tobin's q model. ${ }^{15}$ The slow adjustment of both consumption and investment behavior, in turn, gives rise to humpshaped dynamics of output, as is consistent with the evidence.

A further modification considered important for the empirical performance of the model is the introduction of wage rigidity. In our baseline model we treated as exogenous the cost push shock and emphasized how variation in this shock creates variation in inflationary pressures. The quantitative models endogenize movements in the cost push shock by introducing sticky nominal wages. A popular approach, due to Erceg, Henderson, and Levin (2000), is to introduce staggered nominal wage contracting using the same kind of Calvo/Poisson adjustment process that is used to model staggered price setting. In this environment, the cost push shock in the Phillips curve is no longer exogenous, but instead respond endogenously to any shock that affects the gap between wages and their natural equilibrium values.

New Directions: We now briefly mention several new areas of active research that we find particularly interesting:

1. State-dependent pricing: While the models discussed above are optimizationbased, there is one key aspect in which they are still a black box, namely the timing of price-adjustment. As we have discussed, for reasons of tractability, the models restrict attention to time-dependent pricing rules where the

\footnotetext{
${ }^{15}$ It can be shown that planning lags in investment expenditure can motivate this kind of formulation.
} 
frequency of price adjustment is fixed. Recently, there has been an effort to develop models based on state-dependent pricing. where firms face fixed costs of price adjustment and the adjustment frequency is determined endogenously. Examples include Dotsey, King and Wolman (1999), Golosov and Lucas, (2006), Midrigan (2006) and Gertler and Leahy (2006).

2. Labor market frictions. In existing models all fluctuations in employment are along the intensive margin, i.e., all the variation is in hours per worker. There is no unemployment, per se. The models thus cannot account for the observed fluctuations in unemployment and job flows,. A recent and rapidly growing literature seeks to overcome this shortcoming by developing versions of the new Keynesian model that incorporates the kind of labor market frictions found in the search and matching literature. Examples include Walsh (2003), Trigari (2006), Blanchard and Gali (2006), and Gertler, Sala and Trigari (2007).

3. Financial market imperfections. As we have noted earlier, the baseline model assumes that capital markets are perfect. In many instances, this approximation may be reasonable. However, there are certainly many situations where financial market frictions are highly relevant considerations. In this regard, there is an on-going effort to incorporate financial factors within the kind of quantitative macroeconomic framework we have been discussing, with the aim of better understanding the appropriate role of monetary policy in mitigating the effects of financial crises. Examples include Bernanke, Gertler and Gilchrist (1999), Christiano, Motto, and Rostagno (2006), Monacelli (2006), and Iacoviello (2005). 


\section{Final Thoughts}

We emphasize that the models we have described are still works in progress. Despite the recent successes, we cannot be certain without further experience how resilient these frameworks will prove as new kinds of disturbances hit the economy. Indeed, we fully expect these models to continue to evolve as we accumulate more data and experience more economic shocks. It may be very well the case that important new features are introduced and that ones that are central for performance today are less so in the future. At the same time, while we expect the models to change we think the general approach will not: Quantitative macroeconomic modeling along with its role in the policy-making process is here to stay. 


\section{APPENDIX: A Description of the Monetary Model}

The operational model consists of a set of linear stochastic difference equations. These equations are obtained by taking a log-linear approximation of the equilibrium conditions of the original non-linear model, around the deterministic steady state. That model is in turn a real business cycle model, augmented with monopolistic competition and nominal price rigidities.

At a very general level, there are two key differences from a traditional Keynesian framework. First, all the coefficients of the dynamical system describing the equilibrium are explicit functions of the primitive parameters of the model, i.e. they are explicitly derived from the underlying theory. Second, expected future values of some variables enter the equilibrium conditions, not only current and lagged ones. In other words, expectations matter.

As with the traditional framework, it is convenient to organize the system into three blocks: aggregate demand, aggregate supply, and policy. In this appendix we describe each block, and its mathematical representation.

\section{Aggregate Demand}

The aggregate demand block consists of four equations. A central equation of that block is given by an aggregate goods market clearing condition, i.e. a condition equating output to the sum of the components of aggregate demand. In log-linear form we can write it as:

$$
y_{t}=\gamma_{c} c_{t}+\gamma_{i} i_{t}+d_{t}
$$

where $y$ is output, $c$ is consumption, $i$ is investment, and $d_{t}$ captures the combined effect of other demand components (including government purchases 
and external demand). For simplicity we take those components as exogenous. The four variables are expressed in log deviations from a steady state. $\gamma_{c}$ and $\gamma_{i}$ represent the steady state shares of consumption and investment in output, respectively.

The other relations characterize the behavior of each endogenous component of spending, i.e. consumption and investment. We describe the relation for consumption first, and then turn to investment.

In the baseline model, both capital and insurance markets are perfect. A representative household makes consumption, saving and labor supply decisions in this environment. Within this frictionless setting, the permanent income hypothesis holds perfectly. An implication is that the household strictly obeys a conventional Euler equation that relates the marginal cost of saving (the foregone marginal utility of consumption) to the expected marginal benefit (the expected product of the ex-post real interest rate and the discounted marginal utility of consumption next period). Log-linearizing this equation yields a familiar positive relation between expected consumption growth and the ex-ante real interest rate: Everything else equal, an expected rise in real rates makes the return to saving more attractive, inducing households to reduce current consumption relative to expected future consumption. By rearranging this relation, we obtain the following difference equation for current consumption demand

$$
c_{t}=\sigma\left(r_{t}-E_{t} \pi_{t+1}\right)+E_{t} c_{t+1}+\varepsilon_{c, t}
$$

where $r_{t}$ is the nominal interest rate, $\pi_{t+1}$ denotes the rate of price inflation between $t$ and $t+1$ and $\varepsilon_{c, t}$ is an exogenous preference shock. $E_{t}$ is the 
expectational operator conditional on information at time $t$. Note, in particular, that the previous equation implies that current consumption demand depends negatively on the real interest rate and positively on expected future consumption.

Investment is based on Tobin's $q$ theory. As in the conventional formulation, due to convex costs of adjustment, investment varies exactly with $Q$, the ratio of the shadow value of the marginal unit of installed capital to the replacement value. Sufficient homogeneity is built in both the production and adjustment cost technology to ensure that average and marginal $q$ are the same. Accordingly, by log-linearizing the first order conditions for investment, we obtain a simple linear relation between the investment-capital ratio and average $q$. Formally, aggregate investment, expressed as a ratio to the capital stock $k_{t}$, is a function of (log) Tobin's $q$ and an exogenous disturbance $\varepsilon_{i, t}$.

$$
i_{t}-k_{t}=\eta q_{t}+\varepsilon_{i, t}
$$

We close the aggregate demand sector with an equation describing the evolution of $q$. Typically, the replacement price of capital is either fixed at unity or given exogenously. Accordingly, the endogenous variation in $q$ comes from movement in its shadow value, which is in turn given by the discounted stream of expected returns to capital. By log-linearizing this relation, one obtains an expression that relates $q$ to the expected path of earnings net the expected path of short term real interest rates. Formally,

$$
q_{t}=(1-\beta(1-\delta)) E_{t}\left(y_{t+1}-k_{t+1}-\mu_{p, t+1}\right)-\left(r_{t}-E_{t} \pi_{t+1}\right)+\beta E_{t} q_{t+1}
$$


where $\mu_{p}$ denotes the $(\log )$ price markup. Thus, we see that $q$ depends positively on the expected returns to investment, which in equilibrium is given by the expected marginal product of capital adjusted by the markup (or, equivalently, the equilibrium rental cost) $E_{t}\left(y_{t+1}-k_{t+1}-\mu_{p, t+1}\right)$, and negatively on its opportunity cost, given by the expected real interest rate, $r_{t}-E_{t} \pi_{t+1}$.

\section{Aggregate Supply}

There are six equations in the aggregate supply block. We begin with production. There is a single final good, which is produced under perfect competition using a simple CES aggregator of intermediate goods. The only significant role of the final goods sector (other than transforming all intermediate goods into a single final good) is to generate a downward sloping demand for each intermediate good.

Each firm in the intermediate goods sector is a monopolistic competitor producing a differentiated good, which it sells to the final goods sector. Production of each intermediate good is carried out with a Cobb-Douglas technology that uses capital and labor. Formally, we have

$$
y_{t}=a_{t}+\alpha k_{t}+(1-\alpha) n_{t}
$$

where $k_{t}$ and $n_{t}$ respectively denote $(\log )$ capital and $(\log )$ hours, and $a_{t}$ represents the $(\log )$ of total factor productivity. As in real business cycle models, total factor productivity is assumed to fluctuate over time according to an exogenous process.

Each intermediate goods firm sets the price for its good given the demand curve for its product and taking as given the wage, the rental cost of capital, 
and all other aggregate variables. Critically, firms do not get to readjust the price every period. Instead, they set prices on a staggered basis. For simplicity, it is often assumed that firms use "time-dependent" pricing strategies, where they set prices optimally over an exogenously given horizon. Beyond the significant gain in tractability, the main justification for treating the adjustment frequency as exogenous is that the evidence suggests that the price adjustment frequencies are reasonably stable in low inflation economies. ${ }^{16}$ Of course, this means that the models are mainly relevant for these kinds of environments and are certainly not appropriate for analyzing high inflation economies. At the same time, work is under way to relax the assumption of time-dependent pricing policies and instead introduce state-dependent policies where the frequency of adjustment is determined endogenously.

At any point in time, accordingly, a fraction of firms adjust price and the remaining fraction keep their prices fixed. At any time $t$, firms that are not setting a new price simply adjust output to meet demand, so long as the markup of price over marginal cost remains positive. Given that marginal cost varies positively with shifts in aggregate demand, booms that move output above the natural level cause price markups to decline for firms that do not adjust price, and vice-versa for contractions that move output below the natural level. Thus, what ultimately makes cyclical departures of output from its natural level possible are countercyclical movements in markups stemming from price stickiness. ${ }^{17}$

\footnotetext{
${ }^{16}$ See, e.g. Klenow and Krystov (2005)

${ }^{17}$ Because intermediate goods firms are monopolistic competitors, they have a positive desired markup; i.e. if they were free to set price each period, they would always choose a positive markup. Thus, in the flexible price equilibrium, output is below the socially efficient level. With sticky prices, booms push output toward the efficient level and vice-
} 
Firms that are adjusting choose their respective prices optimally, given the constraint on the frequency of price adjustment. It is typically assumed that the adjustment frequencies obey a simple model originally proposed by Calvo (1983). Each period, a firm is able to adjust its price with probability $1-\theta$. The realization of this draw is independent across firms and over time. This setup captures staggered price setting in the simplest possible way: Each period only the fraction $1-\theta$ of firms are adjusting their price. The average amount of time a firm keeps its price fixed is given by $1 /(1-\theta)$, where the parameter $\theta$ is thus a measure of the degree of price rigidity. Note that $\theta$ may be fixed to match the micro-evidence on price adjustment frequencies.

An important virtue of this approach is that because the adjustment probability is independent of the firm's history it is not necessary to keep track of different vintages of firms, which greatly simplifies aggregation. In this instance, to a first approximation the log price level evolves as a weighted average of the log price set by those firms that adjust and the log of the average price for the firms that do not adjust. The weight on the former being simply the fraction that adjusts, $1-\theta$, while the weight on the latter is $\theta$. Formally, we have

$$
p_{t}=\theta p_{t-1}+(1-\theta) p_{t}^{*}
$$

where $p_{t}^{*}$ is the price set by firms adjusting their price in the current period. ${ }^{18}$

It is straightforward to show that, to a first approximation, adjusting firms choose a price equal to a constant markup over a weighted average of versa for contractions. It is assummed that the boom is never large enough to push output beyond the socially efficient level (i.e. the economy always operates in a region where price exceeds marginal cost).

${ }^{18}$ Note that because the fraction that does not adjust is a random draw, the average price of this population is simply last period's economy-wide average price. 
current and future expected nominal marginal costs. Formally, this can be represented by the difference equations

$$
p_{t}^{*}=(1-\beta \theta)\left[w_{t}-\left(y_{t}-n_{t}\right)\right]+\beta \theta E_{t} p_{t+1}^{*}
$$

where $w_{t}$ denotes the $(\log )$ nominal wage, and $w_{t}-\left(y_{t}-n_{t}\right)$ is the $(\log )$ nominal marginal cost. ${ }^{19}$ Notice that, when solved forward, equation (AS3) implies that firms choose a price to be equal to a discounted sum of current and expected future nominal marginal costs. In that discounted sum, the weight on nominal marginal cost corresponding to any future period depends on the discounted probability that the firm will still have its price fixed at that time. In the limiting case of complete price flexibility (i.e. period by period adjustment), the firm simply sets price as a constant markup over current nominal marginal cost.

The average price markup is given, in logs, by

$$
\mu_{p, t}=p_{t}-\left(w_{t}-\left(y_{t}-n_{t}\right)\right)
$$

As we noted earlier, the countercyclical markup behavior (along with procyclical real marginal cost) emerges because nominal prices are sticky. Many quantitative versions of these models also introduce nominal wage stickiness. This feature is not only consistent with the evidence: Including it tends to improve the overall empirical performance of the model. A common way to add wage rigidity is to assume that there exist monopolistically competitive workers who set nominal wages on a staggered multi-period basis, in close

\footnotetext{
${ }^{19}$ Observe that since the production technology is Cobb-Douglas, nominal marginal costs correspond to nominal unit labor costs, i.e., nominal wages normalized by labor productivity.
} 
analogy to the way firms set prices. In this context one can define a "wage markup" as the wedge between the real wage and the household's marginal rate of substitution between consumption and leisure. This relation can be expressed in log-linear form as follows:

$$
\begin{aligned}
\mu_{w, t} & =\left(w_{t}-p_{t}\right)-m r s_{t} \\
& =\left(w_{t}-p_{t}\right)-\left(\varphi n_{t}+\sigma c_{t}\right)
\end{aligned}
$$

In the frictionless competitive equilibrium this ratio is unity (making the $\log$ of this ratio zero in this case). If worker's have some markup power, then it exceeds unity. With nominal wage rigidity, the wage markup will move countercyclically, similar to the way nominal price rigidities help generate countercyclical price markups. For expositional convenience here, we simply take the wage markup as exogenous, but keeping in mind that this is a stand in for a more explicit formulation.

Finally, there is a relation for the evolution of the capital goods. Next period's capital depends on the creation of new capital goods and what's left of the current capital after depreciation. This is formalized by means of the capital accumulation equation

$$
k_{t+1}=(1-\delta) k_{t}+\delta i_{t}
$$

As we noted earlier, the creation of new capital involves convex adjustment cost, given rise to a variable shadow value of installed capital.

\section{Equilibrium}


We let variables with a "r" denote deviations from their natural values, where the latter are defined as their equilibrium values in the absence of nominal rigidities. We denote natural variables with an " $n$ " superscript. Thus, $\widetilde{x}_{t} \equiv x_{t}-x_{t}^{n}$. Furthermore, we assume for simplicity that percent variations in the capital stock are small, which we approximate by setting $k_{t}=0$ for all $t$.

We can thus rewrite (AD2), (AD4), and in terms of gaps as:

$$
\begin{gathered}
\widetilde{c}_{t}=-\sigma\left(r_{t}-E_{t} \pi_{t+1}-r r_{t}^{n}\right)+E_{t} \widetilde{c}_{t+1} \\
\widetilde{i}_{t}=\eta \widetilde{q}_{t}
\end{gathered}
$$

Combined with (AD1) they imply:

$$
\widetilde{y}_{t}=-\gamma_{c} \widetilde{r r}_{t}^{l}+\gamma_{i} \eta \widetilde{q}_{t}
$$

where

$$
\widetilde{r r}_{t}^{l}=E_{t} \sum_{i=0}^{\infty}\left(r_{t+i}-\pi_{t+1+i}-r r_{t+i}^{n}\right)
$$

Note that (AD3) can be rewritten as

$$
\widetilde{q}_{t}=(1-\beta(1-\delta)) E_{t}\left(\widetilde{y}_{t+1}-\mu_{p, t+1}\right)-\left(r_{t}-E_{t} \pi_{t+1}-r r_{t}^{n}\right)+\beta E_{t} \widetilde{q}_{t+1}
$$

Iterating forward, $\widetilde{q}_{t}$ may be expressed as

$$
\widetilde{q}_{t}=E_{t} \sum_{i=0}^{\infty} \beta^{i}\left[E_{t} \widetilde{z}_{t+1+i}-\left(r_{t+1}-E_{t} \pi_{t+1+1}-r r_{t+i}^{n}\right)\right]
$$

where $\widetilde{z}_{t} \equiv(1-\beta(1-\delta))\left(\widetilde{y}_{t}-\mu_{p, t}\right)$. Thus holding constant current and expected future interest rates, the rent to capital and hence Tobin's $q$ are 
procyclical. Conversely, holding constant the current and expected future rents to capital, $\widetilde{q}_{t}$ moves inversely with current and expected future movements in the interest rate.

We note that equation (??) also makes clear why most central banks are reluctant to adjust interest rates to target asset prices (see, e.g., Bernanke and Gertler (2001)) First, there is no reason to believe that the central bank is better able than the private sector to assess the fundamental determinants of asset prices, given by the right hand side of this equation. Second, there is a circularity problem: $\widetilde{q}_{t}$ is highly sensitive to the current and future path of interest rates. Thus a central bank that mechanically adjusts interest rates to stabilize asset prices may wind up introducing undesired volatility to either interest rates or asset prices, or both.

Furthermore, combining (AS2), (AS3), and (AS4) we obtain the aggregate supply equation:

$$
\pi_{t}=\beta E_{t} \pi_{t+1}-\lambda \mu_{p, t}
$$

where

$$
\begin{aligned}
\mu_{p, t} & =-\left(\frac{\alpha+\varphi}{1-\alpha}+\sigma\right) \widetilde{y}_{t}-\sigma\left(\widetilde{c}_{t}-\widetilde{y}_{t}\right)-\mu_{w, t} \\
& =-\left(\frac{\alpha+\varphi}{1-\alpha}+\frac{\sigma}{\gamma_{c}}\right) \widetilde{y}_{t}+\frac{\gamma_{i}}{\gamma_{c}} \sigma \eta \widetilde{q}_{t}-\mu_{w, t}
\end{aligned}
$$

We can thus rewrite the inflation equation in terms of the output gap as

$$
\pi_{t}=\beta E_{t} \pi_{t+1}+\kappa \widetilde{y}_{t}+u_{t}
$$


where $u_{t} \equiv \lambda\left(\mu_{w, t}-\frac{\gamma_{i}}{\gamma_{c}} \sigma \eta \widetilde{q}_{t}\right)$ and $\kappa \equiv \lambda\left(\frac{\alpha+\varphi}{1-\alpha}+\frac{\sigma}{\gamma_{c}}\right)$.

Finally, we can represent monetary policy by means of a rule of the form:

$$
r_{t}=(1-\rho)\left(r r_{t}^{n}+\phi_{\pi} \pi_{t}+\phi_{y} \widetilde{y}_{t}\right)+\rho r_{t-1}
$$

Equations (5), (6), and (7) provide the canonical representation of the equilibrium dynamics of the monetary model used in a variety of applications in the literature.

For the simulations presented in the text, we used the following parameter values: $\alpha=0.33 ; \beta=0.99 ; \delta=0.99 ; \sigma=2.0 ; \varphi=1.0 ; \theta=0.75 ; \gamma_{c}=0.63$; $\gamma_{i}=0.15 ; \eta=0.5 ; \phi_{\pi}=1.5 ; \rho=0.80$. In addition, we assumed that the autocorrelation of the cost push shock was 0.95 . 


\section{References}

Alvarez, Luis J. (2007): "What do micro price data tell us on the validity of the New Keynesian Phillips Curve?," Bank of Spain, unpublished manuscript.

Ball, Laurence and David H. Romer (1990): "Real Rigidities and the Nonneutrality of Money," Review of Economic Studies 57, 183-203.

Bayoumi, Tam (2004): "GEM: A New International Macroeconomic Model," IMF Occasional Paper no. 239.

Bernanke, Ben, Mark Gertler and Simon Gilchrist (1999), "The Financial Accelerator in a Quantitative Business Cycle Framework," Handbook of Macroeconomics, John Taylor and Michael Woodford, editors.

Blanchard, Olivier J. and Jordi Galí (2006): "A New Keynesian Model with Unemployment," mimeo.

Christiano, Lawrence J., Martin Eichenbaum, and Charles L. Evans (2005): "Nominal Rigidities and the Dynamic Effects of a Shock to Monetary Policy," Journal of Political Economy, vol. 113, no. 1, 1-45.

Christiano, Lawrence J., Roberto Motto and Massimo Rostagno (2006): "Monetary Policy and Stock Market Boom-Bust Cycles," mimeo.

Clarida, Richard, Jordi Galí, and Mark Gertler (1998): "Monetary Policy Rules in Practice: Some International Evidence" European Economic Review, vol. $42,1033-1067$.

Clarida, Richard, Jordi Galí, and Mark Gertler (1999): "The Science of Monetary Policy: A New Keynesian Perspective," Journal of Economic Literature, vol. 37, 1661-1707.

Clarida, Richard, Jordi Galí, and Mark Gertler (2000): "Monetary Policy 
Rules and Macroeconomic Stability: Evidence and Some Theory," Quarterly Journal of Economics, vol. 105, issue 1, 147-180.

Coenen, Günter, Peter McAdam, Roland Straub (2006): "Tax Reform and Labour Market Performance in the Euro Area: A Simulation-Based Analysis unsing the New Area-Wide Model," Journal of Economic Dynamics and Control, forthcoming.

Cogley, Timothy, and Argia M. Sbordone (2005): "A Search for a Structural Phillips Curve," Federal Reserve Bank of New York, mimeo.

Dixit, Avinash, and Joseph Stiglitz (1977): "Monopolistic Competition and Optimum Product Diversity," American Economic Review, 67, 297-308.

Dotsey, Michael, Robert G. King, and Alexander L. Wolman (1999): "State Dependent Pricing and the General Equilibrium Dynamics of Money and Output," Quarterly Journal of Economics, vol. CXIV, issue 2, 655-690.

Erceg, Christopher J., Luca Guerrieri, Christopher Gust (2006): "SIGMA: A New Open Economy Model for Policy Analysis," International Journal of Central Banking, vol. 2 (1), 1-50.

Fischer, Stanley (1977): "Long Term Contracts, Rational Expectations, and the Optimal Money Supply Rule," Journal of Political Economy, 85 (1), 191-205.

Fuhrer, Jeffrey C., and George R. Moore (1995): "Inflation Persistence", Quarterly Journal of Economics, No. 440, February, pp 127-159.

Galí, Jordi (2007): Monetary Policy, Inflation, and the Business Cycle, unpublished monograph.

Galí, Jordi and Mark Gertler (1999): "Inflation Dynamics: A Structural Econometric Analysis," Journal of Monetary Economics, vol. 44, no. 2, 
195-222.

Galí, Jordi, Mark Gertler, David López-Salido (2005): "Robustness of the Estimates of the Hybrid New Keynesian Phillips Curve," Journal of Monetary Economics, vol. 52, issue 6, 1107-1118.

Galí, Jordi and Pau Rabanal (2004): "Technology Shocks and Aggregate Fluctuations: How Well Does the RBC Model Fit Postwar U.S. Data?," NBER Macroeconomics Annual 2004, 225-288.

Gertler, Mark and John Leahy (2006): "A Phillips Curve with an S-s Foundation," mimeo.

Gertler, Mark, Luca Sala and Antonella Trigari; (2007) "An Estimated Monetary DSGE Model with Unemployment and Staggered Nash Wage Bargaining.

Golosov, Mikhail, and Robert E. Lucas Jr. (2007): "Menu Costs and Phillips Curves," Journal of Political Economy, vol. 115 (2), 171-199.

Goodfriend, Marvin and Robert G. King (1997): "The New Neoclassical Synthesis and the Role of Monetary Policy," NBER Macroeconomics Annual, $231-282$.

Hall, Robert (2005): "Employment Fluctuations with Equilibrium Wage Stickiness," American Economic Review vol. 95, no. 1, 50-64.

Iacoviello, Matteo (2006): "House Prices, Borrowing Constraints and Monetary Policy in the Business Cycle," American Economic Review, 95, 3 739-764.

Klenow, Peter J., Oleksiy Kryvtsov (2005): "State-Dependent or TimeDependent Pricing: Does it Matter for Recent U.S. Inflation?" NBER WP\# 11043. 
Lucas, Robert E. (1976): "Econometric Policy Evaluation: A Critique," Carnegie-Rochester conference Series on Public Policy, vol. 1, 19-46.

Mankiw, N. Gregory and David Romer (1991): New Keynesian Economics, MIT Press (Cambridge, MA).

Midrigan, Virgiliu (2006): "Menu costs, Multi-Product Firms, and Aggregate Fluctuations," mimeo.

Monacelli, Tommaso (2006): "Optimal Monetary Policy with Collateralized Household Debt and Borrowing Constraints," mimeo.

Nakamura, Emi and Jon Steinsson (2006): "Five Facts about Prices: A Reevaluation of Menu Costs Models," Harvard University, mimeo.

Primiceri, Giorgio, Ernst Schaumberg and Andrea Tambalotti (2006): "Intertemporal Disturbances," mimeo.

Rotemberg, Julio and Michael Woodford (1999): "Interest Rate Rules in an Estimated Sticky Price Model," in J.B. Taylor ed., Monetary Policy Rules, University of Chicago Press.

Sargent, Thomas (1981): "Interpreting Economic Time Series," Journal of Political Economy, 99 (2), 213-248.

Sims, Christopher (1980): "Macroeconomics and Reality," Econometrica, vol. 48, no. 1, 1-48.

Smets, Frank, and Raf Wouters (2003): "An Estimated Dynamic Stochastic General Equilibrium Model of the Euro Area," Journal of the European Economic Association, vol 1, no. 5, 1123-1175.

Smets, Frank, and Raf Wouters (2006): "Shocks and Frictions in US Business Cycles: A Bayesian DSGE Approach," mimeo.

Taylor, John B. (1979): "Estimation and Control of a Macroeconomic 
Model with Rational Expectations," Econometrica, 47 (5), 1267-1286.

Taylor, John B. (1980): "Aggregate Dynamics and Staggered Contracts," Journal of Political Economy, 88, 1-23.

Taylor, John B. (1993): "Discretion versus Policy Rules in Practice," Carnegie-Rochester Series on Public Policy 39, 195-214.

Taylor, John B. (1999): "An Historical Analysis of Monetary Policy Rules," in J.B. Taylor ed., Monetary Policy Rules, University of Chicago Press.

Trigari, Antonella (2005): "Equilibrium Unemployment, Job Flows, and Inflation Dynamics," ECB WP\#304.

Walsh, Carl (2005): "Labor Market Search, Sticky Prices, and Interest Rate Rules", Review of Economic Dynamics, 8, 829-849

Woodford, Michael (2001): "The Taylor Rule and Optimal Monetary Policy," American Economic Review vol. 91, no. 2, 232-237.

Woodford, Michael (2003): Interest and Prices: Foundations of a Theory of Monetary Policy, Princeton University Press.(Princeton, New Jersey).

Woodford, Michael (2006): "How Important is Money in the Conduct of Monetary Policy?," unpublished manuscript. 
Table 1

Responses of Inflation and Output to a Cost Push Shock:

\section{Credible vs. Not Credible Central Bank}

\begin{tabular}{|l||l|l|l|l|}
\hline \multirow{2}{*}{ Time after shock } & \multicolumn{2}{c|}{ Credible } & \multicolumn{2}{c|}{ Not Credible } \\
\cline { 2 - 5 } & Inflation & Output & Inflation & Output \\
\hline \hline Zero & $0.20 \%$ & $-0.60 \%$ & $5.20 \%$ & $-0.60 \%$ \\
\hline One Year & $0.15 \%$ & $-0.50 \%$ & $4.40 \%$ & $-0.50 \%$ \\
\hline Two Years & $0.10 \%$ & $-0.40 \%$ & $3.50 \%$ & $-0.40 \%$ \\
\hline
\end{tabular}


Table 2

Responses of Inflation and Output to a Productivity Shock: with and without adjustments for movements in the Natural Interest Rate

\begin{tabular}{|l||l|c|c|c|}
\hline \multirow{2}{*}{\multicolumn{1}{|c||}{ Time After Shock }} & \multicolumn{2}{c|}{ With Adjustment } & \multicolumn{2}{c|}{ Without Adjustment } \\
\cline { 2 - 5 } & Inflation & Output & Inflation & Output \\
\hline \hline Zero & $0.00 \%$ & $0.60 \%$ & $0.24 \%$ & $1.05 \%$ \\
\hline One Year & $0.00 \%$ & $1.20 \%$ & $-0.07 \%$ & $1.25 \%$ \\
\hline Two Years & $0.00 \%$ & $1.10 \%$ & $-0.10 \%$ & $1.10 \%$ \\
\hline
\end{tabular}

